Article

\title{
Fucosylated Chondroitin Sulfates from the Sea \\ Cucumbers Paracaudina chilensis and Holothuria hilla: Structures and Anticoagulant Activity
}

\author{
Nadezhda E. Ustyuzhanina ${ }^{1, *}$, Maria I. Bilan ${ }^{1}$, Andrey S. Dmitrenok ${ }^{1}{ }^{1}$, \\ Alexandra S. Silchenko ${ }^{2}$, Boris B. Grebnev ${ }^{2}$, Valentin A. Stonik ${ }^{2}$, Nikolay E. Nifantiev ${ }^{1}$ and \\ Anatolii I. Usov 1,* \\ 1 N.D. Zelinsky Institute of Organic Chemistry, Russian Academy of Sciences, Leninsky Prospect 47, \\ 119991 Moscow, Russia; bilan@ioc.ac.ru (M.I.B.); dmt@ioc.ac.ru (A.S.D.); nen@ioc.ac.ru (N.E.N.) \\ 2 G.B. Elyakov Pacific Institute of Bioorganic Chemistry, Far Eastern Branch of the Russian \\ Academy of Sciences, Prospect 100 let Vladivostoku 159, 690022 Vladivostok, Russia; \\ sialexandra@mail.ru (A.S.S.); grebnev_bor@mail.ru (B.B.G.); stonik@piboc.dvo.ru (V.A.S.) \\ * Correspondence: ustnad@gmail.com (N.E.U.); usov@ioc.ac.ru (A.I.U.); Tel.: +7-495-135-8784 (N.E.U.)
}

Received: 29 September 2020; Accepted: 26 October 2020; Published: 28 October 2020

\begin{abstract}
Fucosylated chondroitin sulfates (FCSs) PC and HH were isolated from the sea cucumbers Paracaudina chilensis and Holothuria hilla, respectively. The purification of the polysaccharides was carried out by anion-exchange chromatography on a DEAE-Sephacel column. The structural characterization of the polysaccharides was performed in terms of monosaccharide and sulfate content, as well as using a series of nondestructive NMR spectroscopic methods. Both polysaccharides were shown to contain a chondroitin core $[\rightarrow 3)-\beta-\mathrm{D}-\mathrm{GalNAc}(\mathrm{N}$-acethyl galactosamine)-( $1 \rightarrow 4)-\beta$-D-GlcA (glucuronic acid)- $(1 \rightarrow]_{n}$, bearing sulfated fucosyl branches at O-3 of every GlcA residue in the chain. These fucosyl residues were different in their pattern of sulfation: PC contained Fuc2S4S and Fuc4S in a ratio of 2:1, whereas HH included Fuc2S4S, Fuc3S4S, and Fuc4S in a ratio of 1.5:1:1. Moreover, some GalNAc residues in $\mathbf{H H}$ were found to contain an unusual disaccharide branch Fuc4S- $(1 \rightarrow 2)$-Fuc3S4S-( $1 \rightarrow$ at O-6. Sulfated GalNAc4S6S and GalNAc4S units were found in a ratio of 3:2 in PC and 2:1 in HH. Both polysaccharides demonstrated significant anticoagulant activity in a clotting time assay, which is connected with the ability of these FCSs to potentiate the inhibition of thrombin and factor Xa in the presence of anti-thrombin III (ATIII) and with the direct inhibition of thrombin in the absence of any cofactors.
\end{abstract}

Keywords: sea cucumber; Holothuria hilla; Paracaudina chilensis; fucosylated chondroitin sulfate; anticoagulant activity

\section{Introduction}

Fucosylated chondroitin sulfates (FCSs) are the unique polysaccharides found exclusively in the body walls of sea cucumbers. These biopolymers are composed of D-glucuronic acid, $N$-acetyl-D-galactosamine, L-fucose, and sulfate residues [1-3]. A chondroitin core of FCSs $[\rightarrow 3)-\beta$-D-GalNAc- $(1 \rightarrow 4)-\beta$-D-GlcA- $(1 \rightarrow]_{n}$ contains $\alpha$-L-fucosyl branches attached to O-3 of GlcA or to O-6 of GalNAc [1-6]. Sulfate groups may occupy different positions of GalNAc, Fuc, and even GlcA residues. Depending on the species of sea cucumber, FCSs include GalNAc units sulfated at O-4 or at both O-4 and O-6; fucosyl branches Fuc2S4S, Fuc3S4S, and Fuc4S; as well as GlcA residues sulfated at O-3 or at both O-2 and O-3 [3-8]. In addition, difucosyl branches attached to O-3 of GlcA are known as 
very rare structural fragments of FCSs. Thus, FCS from Holothuria (Ludwigothuria) grisea was shown to contain the branch $\alpha$-L-Fuc- $(1 \rightarrow 2)-\alpha$-L-Fuc3S- $\rightarrow$ [9]. The branch $\alpha$-L-Fuc- $(1 \rightarrow 2)-\alpha$-L-Fuc3S4S- $1 \rightarrow$ was observed in FCS from Eupentacta fraudatrix [8]. FCS from Holothuria lentiginosa contains the fragment $\alpha$-L-Fuc- $(1 \rightarrow 3)-\alpha$-L-Fuc $4 S-1 \rightarrow$ linked also to O-3 of GlcA [10].

The fine structure of FCSs significantly influences biological activity, which is connected with the interaction of polysaccharides with different proteins. Thus, the intensively studied anticoagulant activity of FCSs was shown to be determined by their ability to potentiate the inhibition of thrombin and factor Xa in the presence of anti-thrombin III (ATIII) [1,3,5,6,11-14]. Other mechanisms mediated by heparin cofactor II and FXase were also considered [15-17]. The presence of fucosyl branches sulfated at O-4 in FCSs was found to be essential for the anticoagulant effect $[13,18]$. The anti-inflammatory activity of FCSs is connected with their binding to P- and L-selectins [19]. Recently, the anti-angiogenic effect of FCS from Hemioedema spectabilis was demonstrated in vitro [20], which is probably mediated by the interaction of the polysaccharide with growth factors [21].

In this communication, we describe the structural characterization of two FCSs (PC and $\mathbf{H H}$ ) isolated from the sea cucumbers Paracaudina chilensis and Holothuria hilla, respectively. The anticoagulant activity of these polysaccharides was studied in vitro.

The sea cucumber Holothuria hilla, belonging to the order Holothuriida, is a widely distributed species in the South China Sea, especially near the shore of Fujian Province of China, Dongshan Island, and the Vietnamese seashore. The chemical composition of this sea cucumber was studied in 2006-2007 by Chinese researchers, who isolated and elucidated the structures of three novel triterpene glycosides, hillasides A-C [22,23], together with the previously known holothurins A and B. These glycosides are xylosides of holostane aglycones, differing in their structures of aglycones and carbohydrate side chains. It is interesting to mention that one of them, hillaside $C$, contained a disaccharide chain composed of two xylose residues, which was found in the triterpene glycosides of sea cucumbers for the first time. Hillasides were shown to exhibit significant cytotoxic activity (in vitro). The polysaccharides of $H$. hilla have not been previously studied.

Paracaudina chilensis belongs to the order Molpadiida, the representatives of which have been poorly studied in regard to their chemistry. A new triterpene glycoside, caudinoside A, was isolated from this sea cucumber (named Paracaudina ransonetii) in 1986. The structure of native aglycone, $3 \beta$-hydroxy-16-ketoholosta-9(11),25-diene, and the monosaccharide composition of the carbohydrate chain (xylose, quinovose, glucose, and 3-O-methylglucose in the ratio of 1:1:3:1) were established, but the whole chemical structure of caudinoside A remains unelucidated [24]. In addition, the amino acid sequence of the major globin isolated from coelomic cells of P. chilensis was determined [25], and gelatin hydrolysates were shown to possess antioxidant activity, demonstrating a reasonable radical scavenging effect and preventing the damage of rabbit liver and mitochondria (the species name was erroneously written as 'chinens' in this publication) [26]. As in the case of $H$. hilla, the polysaccharide composition of $P$. chilensis has not been investigated previously.

\section{Results and Discussion}

Crude extracts of sulfated polysaccharides were obtained from the body walls of sea cucumbers Paracaudina chilensis and Holothuria hilla by the conventional solubilization of biomass in the presence of papain [27] followed by the treatment of the extract with hexadecyl-trimethylammonium bromide to precipitate the sulfated components, which were then transformed into water-soluble sodium salts by stirring the components with $\mathrm{NaI}$ in ethanol. According to their composition, crude preparations contained sulfated fucans and FCS as the main components. Both crude extracts were subjected to anion-exchange chromatography on a DEAE-Sephacel column. The fractions eluted with $1.0 \mathrm{M} \mathrm{NaCl}$ were designated as PC for P. chilensis and $\mathbf{H H}$ for $H$. hilla. These preparations contained GlcA, GalNAc, Fuc, and sulfate in ratios (Table 1) typical for holothurian FCSs. The detection of minor Gal and GlcN in hydrolysates was explained by the possible presence of small amounts of other glycosaminoglycans, which could not be eliminated by anion-exchange chromatography. The molecular weights of 
the polysaccharides were estimated as $28.9 \mathrm{kDA}$ for PC and $26.7 \mathrm{kDa}$ for $\mathrm{HH}$ by gel-permeation chromatography [28].

Table 1. Percentages of crude polysaccharide preparations and composition of fucosylated chondroitin sulfates PC and $\mathbf{H H}$ (in $w / w \%$ ).

\begin{tabular}{cccccccc}
\hline Polysaccharide & Yield & Fuc & GlcA & SO $_{3}$ Na & GlcN & GalN & Gal \\
\hline HH & 16.1 & 10.8 & 13.3 & 21.2 & - & 10.7 & 1.6 \\
\hline PC & 20.9 & 10.9 & 11.4 & 21.3 & 1.2 & 8.8 & 4.3 \\
\hline
\end{tabular}

The structures of polysaccharides PC and $\mathbf{H H}$ were characterized in more detail using NMR spectroscopic methods. The presence of Fuc, GalNAc, and GlcA units in both polysaccharides was confirmed by the characteristic values of chemical shifts of C- 6 for Fuc $(\delta 17.2 \mathrm{ppm})$ and GlcA $(\delta 176.0 \mathrm{ppm})$, as well as of C-2 for GalNAc $(\delta 52.7 \mathrm{ppm})$ in ${ }^{13} \mathrm{C}$ NMR spectra (Figure 1). The anomeric regions in the ${ }^{1} \mathrm{H}$ NMR spectra of the polysaccharides were quite different, indicating the presence of different fucosyl branches (Figure 2).

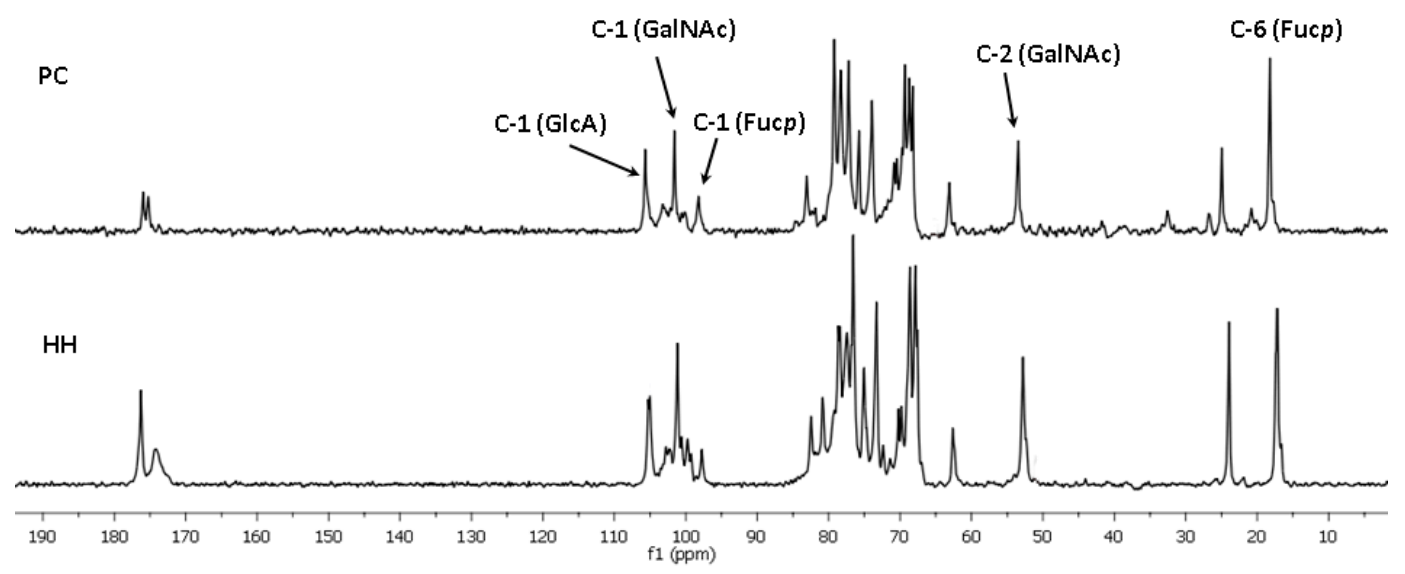

Figure 1. The ${ }^{13} \mathrm{C}$ NMR spectra of the fucosylated chondroitin sulfates $\mathbf{P C}$ and $\mathbf{H H}$.

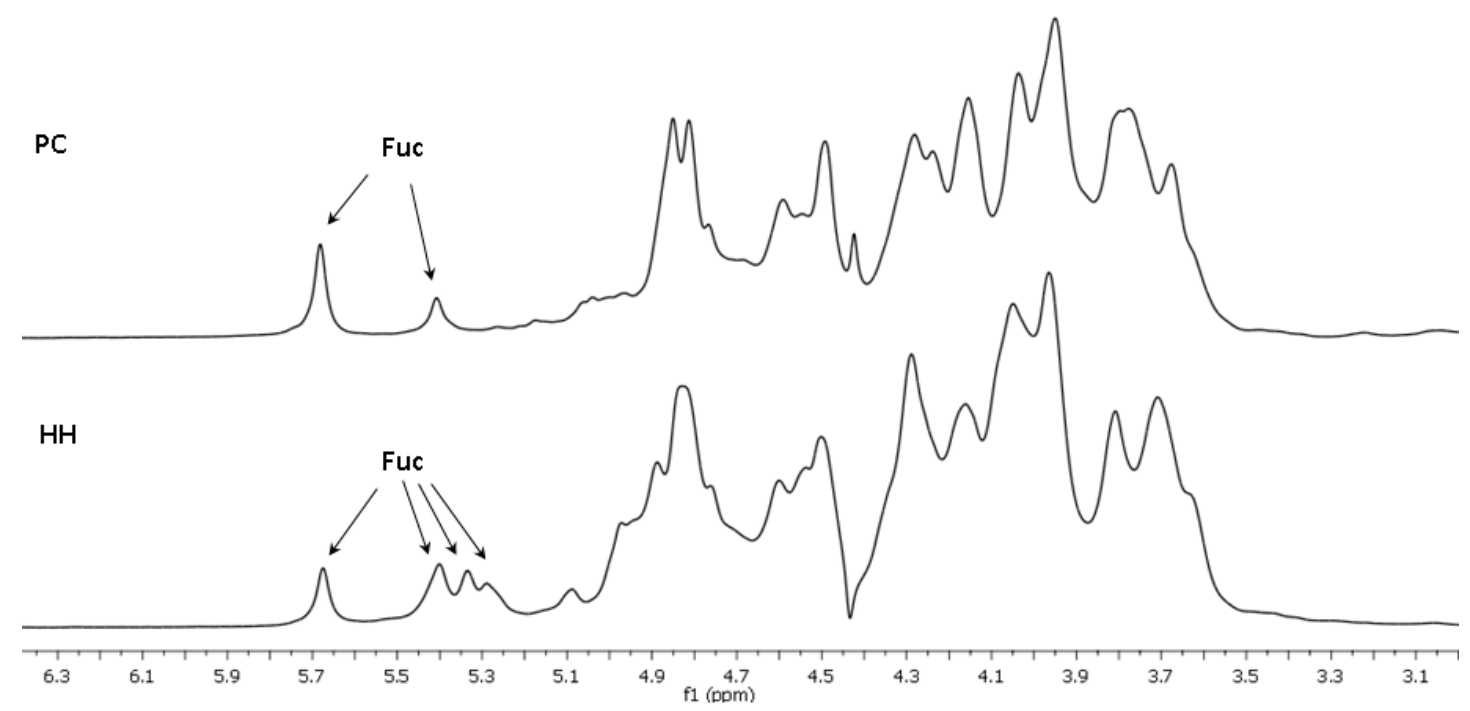

Figure 2. Fragments of ${ }^{1} \mathrm{H}$ NMR spectra of the fucosylated chondroitin sulfates $\mathbf{P C}$ and $\mathbf{H H}$.

The application of 2D NMR experiments correlation spectroscopy (COSY), total correlation spectroscopy (TOCSY), heteronuclear single quantum coherence (HSQC), and rotating-frame nuclear Overhauser effect spectroscopy (ROESY) led to assigning all of the signals of the major components 
in the ${ }^{1} \mathrm{H}$ and ${ }^{13} \mathrm{C}$ NMR spectra of the polysaccharides (Figures 3 and 4 and Figures S1-S3, Table 2). Analysis of the spectra of PC revealed the similarity of its structure to those described previously for FCS from other species of sea cucumbers $[4,19,29]$. Thus, the signals of GlcA, GalNAc, and Fuc units were related to the core $[\rightarrow 3)-\beta$-D-GalNAc- $(1 \rightarrow 4)-\beta$-D-GlcA- $(1 \rightarrow]_{n}$, bearing fucosyl branches at O-3 of every GlcA unit (see repeating unit I in Figure 3) $[4,19]$. There were two fucosyl units Fuc2S4S (D) and Fuc4S (F) that differed in pattern of sulfation, which was indicated by the downfield chemical shifts of the signals of respective protons in the ${ }^{1} \mathrm{H}$ NMR spectrum (Table 2). The ratio of units $\mathbf{D}$ and $\mathbf{F}$ was determined using the integral intensities of the respective $\mathrm{H}-1$ signals and was found to be 2:1. The linkages between the fucosyl units and O-3 of GlcA were confirmed by the correlation H-1(Fuc)-H-3(GlcA) in the ROESY spectrum (Figure S2). Sulfated GalNAc4S6S (B) and GalNAc4S (C) units were found in an approximate ratio of 3:2 in PC by integration of the intensities of the cross-peaks related to $\mathrm{H}-6-\mathrm{C}-6$ interaction in units $\mathbf{B}$ and $\mathbf{C}$ in the HSQC spectrum.
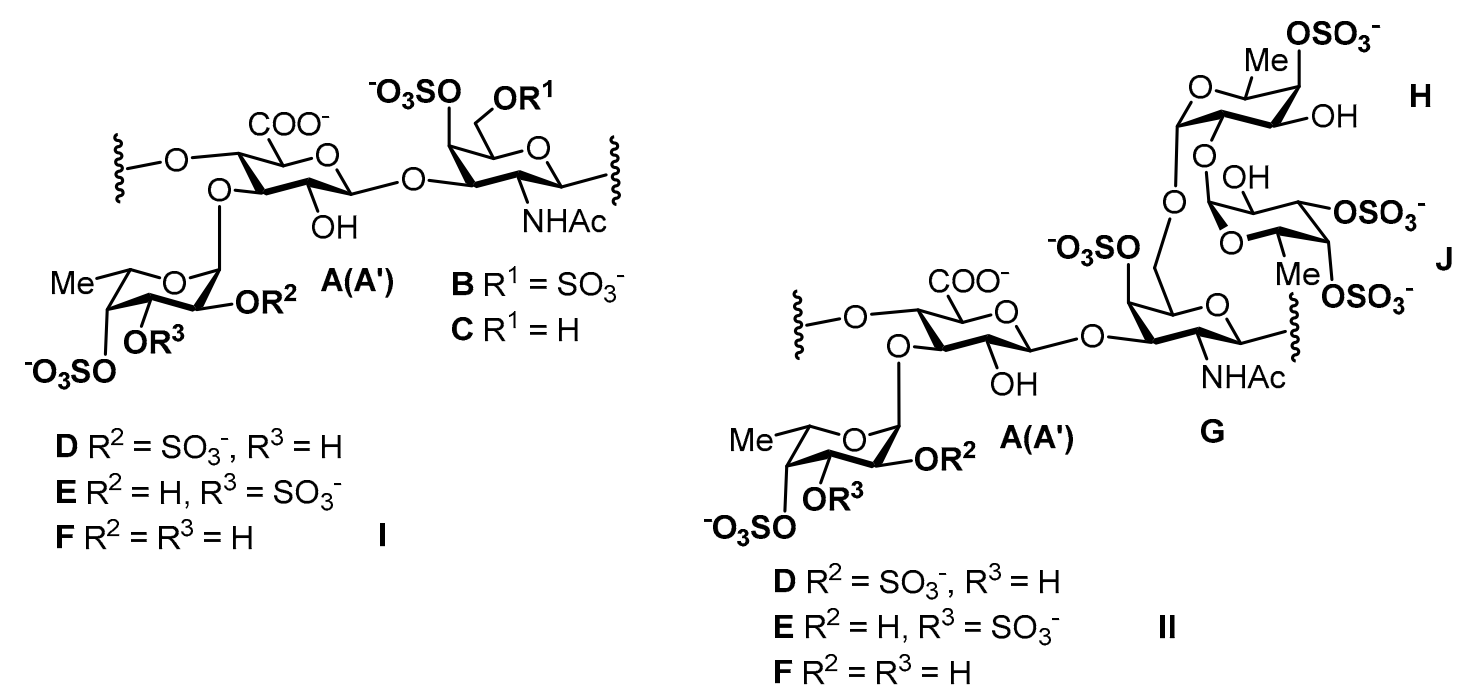

Figure 3. Repeating blocks of fucosylated chondroitin sulfates PC (units A-D, F) and HH (units A-J). Unit A bears Fuc2S4S (D), whereas unit $\mathbf{A}^{\prime}$ bears Fuc3S4S (E) or Fuc4S (F).

The structure of polysaccharide $\mathbf{H H}$ was more complex than that of PC. Two branched repeating blocks I and II were determined in HH (Figure 3). The first one was typical for all FCSs and contained three different fucosyl branches Fuc2S4S (D), Fuc3S4S (E), and Fuc4S (F) in a ratio of 1.5:1:1 (calculated using the integral intensities of the respective H-1 signals, Figure S4). Units GalNAc4S6S (B) and GalNAc4S (C) were found in a ratio of 2:1. The repeating block II along with the fucosyl residue at O-3 of GlcA contained the unusual difucosyl branch attached to O- 6 of GalNAc(G) and formed by units $\mathbf{H}$ and $\mathbf{J}$. The chemical shift of the $\mathrm{H}-1$ signal of unit $\mathbf{H}(\delta 5.28 \mathrm{ppm})$ differed from those of units D, E, and F. This led to the assessment of the signals of the spin system of unit $\mathbf{H}$ using the COSY, TOCSY, and ROESY experiments (Figures S1-S3) and allowed for the determination of the signals of the respective carbon atoms from the HSQC spectrum (Figure 4B). The attachment of unit $\mathbf{H}$ to O-6 of GalNAc $(\mathbf{G})$ was confirmed by the presence of the cross-peak $\mathrm{H} 1(\mathbf{H})-\mathrm{H} 6(\mathbf{G})$ in the ROESY spectrum. The downfield chemical shift of the C-2 signal of $\mathbf{H}(\delta 72.8 \mathrm{ppm})$ indicated the position of glycosylation (compared with $\delta 69.8 \mathrm{ppm}$ for Fuc $4 S$ F). Detailed analysis of the ROESY spectrum revealed one more fucosyl unit $\mathbf{J}(\delta 5.41 \mathrm{ppm})$ linked to $\mathrm{O}-2$ of residue $\mathbf{H}$, as the cross-peak $\mathrm{H} 1(\mathrm{~J})-\mathrm{H} 2(\mathbf{H})$ was detected. The positions of sulfate groups in units $\mathbf{H}$ and $\mathbf{J}$ were determined by the downfield chemical shifts of signals of the respective protons. Therefore, the presence of the unusual branch Fuc4S-(1 $\rightarrow 2)$-Fuc3S4S-( $\rightarrow$ linked to O-6 of GalNAc was confirmed. The ratio of units $\mathbf{H}$ and $\mathbf{E}$ was estimated to be about 1:1 (Figure S4). Previously, difucosyl branches in holothurian FCSs were found to be attached to O-3 of GlcA but not to O-6 of GalNAc [8-10]. 


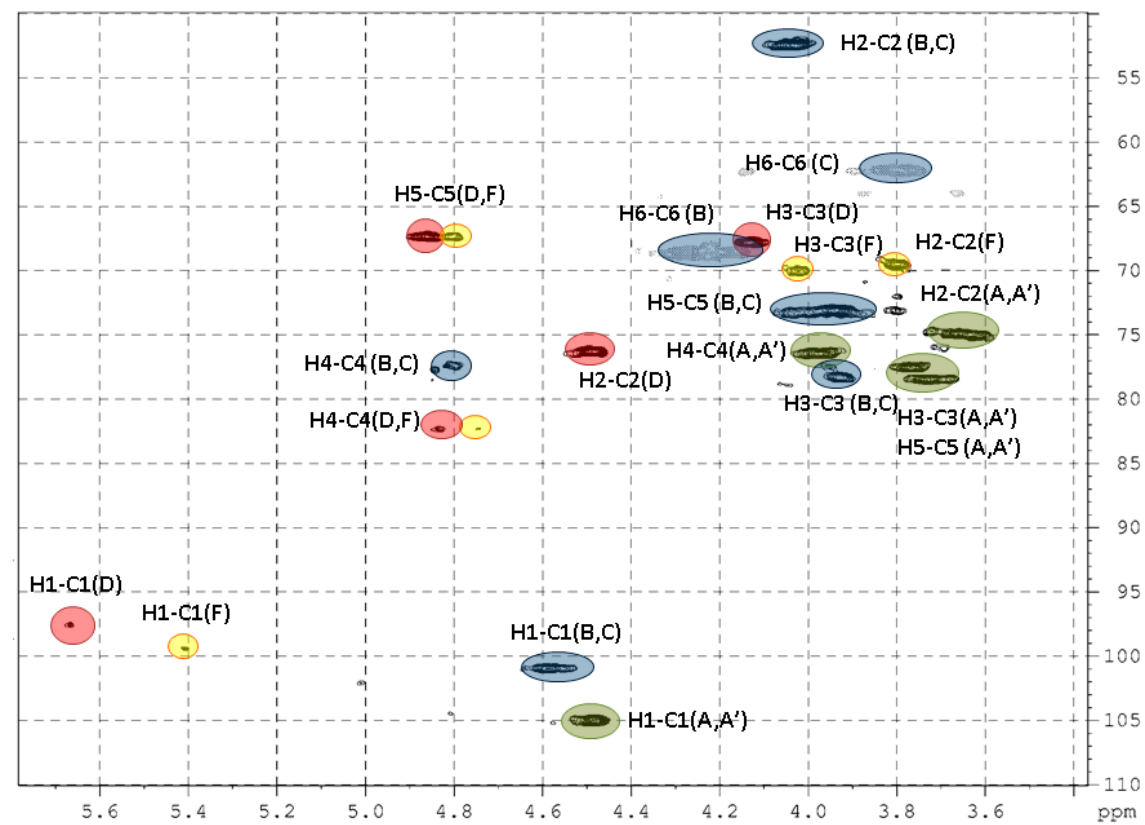

(A)

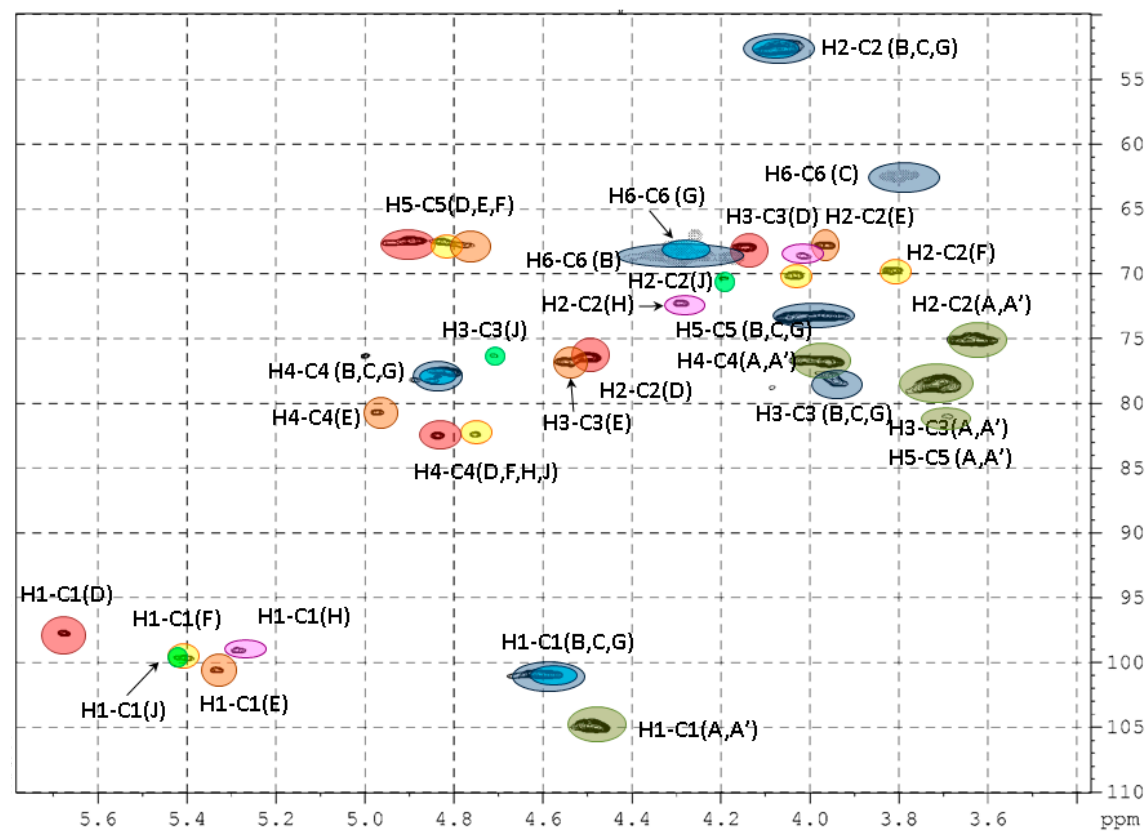

(B)

Figure 4. The HSQC NMR spectra of polysaccharides PC (A) and HH (B).

FCSs are known to demonstrate anticoagulant activity; therefore, we have studied two new polysaccharides PC and $\mathbf{H H}$ as anticoagulant agents in vitro. Heparin and low-molecular-weight heparin (enoxaparin) were used as standards. In addition, we have studied FCS CD, isolated previously from the sea cucumber Cucumaria djakonovi [30]. The latter polysaccharide includes the linear non-fucosylated disaccharide fragments $\rightarrow 3)-\beta$-D-GalNAc4S6S- $(1 \rightarrow 4)-\beta-\mathrm{D}-\mathrm{GlcA}-(1 \rightarrow$, $\rightarrow 3)-\beta$-D-GalNAc4S-( $1 \rightarrow 4)-\beta$-D-GlcA- $(1 \rightarrow$, and $\rightarrow 3)-\beta$-D-GalNAc6S- $(1 \rightarrow 4)-\beta$-D-GlcA- $(1 \rightarrow$ along with the branched unit I (Figure 3). In the clotting time assay (activated partial thromboplastin time (APTT) test), the effects of PC and HH were higher than that of enoxaparin but lower than that of heparin, whereas polysaccharide $\mathbf{C D}$ was less active than enoxaparin (Figure 5A). The values of 2APTT (the concentration that led to a 2-fold increase of time of clot formation) were $0.8 \pm 0.1 \mu \mathrm{g} / \mathrm{mL}$ for heparin, $2.5 \pm 0.1 \mu \mathrm{g} / \mathrm{mL}$ for $\mathbf{H H}, 2.8 \pm 0.1 \mu \mathrm{g} / \mathrm{mL}$ for PC, $3.7 \pm 0.2 \mu \mathrm{g} / \mathrm{mL}$ for enoxaparin, and $5.0 \pm 0.1 \mu \mathrm{g} / \mathrm{mL}$ for CD. 
Table 2. Chemical shifts of the signals in the ${ }^{1} \mathrm{H}$ and ${ }^{13} \mathrm{C}$ NMR spectra of the fucosylated chondroitin sulfates PC and $\mathbf{H H}$ (the bold numerals indicate the positions of sulfate).

\begin{tabular}{|c|c|c|c|c|c|c|}
\hline Residue & $\mathrm{H} 1 / \mathrm{C} 1$ & $\mathrm{H} 2 / \mathrm{C} 2$ & Н3/С3 & $\mathrm{H} 4 / \mathrm{C} 4$ & $\mathrm{H} 5 / \mathrm{C} 5$ & H6/C6 \\
\hline \multirow{2}{*}{$\mathrm{A} \rightarrow 4)-\beta-\mathrm{D}-\mathrm{Glc} p \mathrm{~A}-(1 \rightarrow$} & $4.48 /$ & $3.64 /$ & $3.72 /$ & $3.96 /$ & $3.70 /$ & - \\
\hline & 105.0 & 75.0 & 77.8 & 76.6 & 78.1 & 176.0 \\
\hline \multirow{2}{*}{$\left.\mathbf{A}^{\prime} \rightarrow 4\right)-\beta-\mathrm{D}-\mathrm{Glc} p \mathrm{~A}-(1 \rightarrow$} & $4.48 /$ & $3.60 /$ & $3.68 /$ & $4.00 /$ & $3.71 /$ & - \\
\hline & 105.0 & 75.0 & 80.7 & 76.6 & 78.1 & 176.0 \\
\hline \multirow{2}{*}{$\mathbf{B} \rightarrow 3)-\beta-\mathrm{D}-\mathrm{Gal} p$ NAc $4 S 6 S-(1 \rightarrow$} & $4.58 /$ & $4.07 /$ & $3.95 /$ & $4.81 /$ & $4.00 /$ & 4.33 \\
\hline & 100.9 & 52.7 & 77.9 & 77.2 & 73.2 & $\begin{array}{l}4.20 \\
68.5\end{array}$ \\
\hline \multirow{2}{*}{$\mathrm{C} \rightarrow 3)-\beta-\mathrm{D}-\mathrm{Gal} p \mathrm{NAc} 4 S-(1 \rightarrow$} & $4.58 /$ & $4.07 /$ & $3.95 /$ & $4.81 /$ & $4.02 /$ & $3.81 /$ \\
\hline & 100.9 & 52.7 & 77.9 & 77.2 & 76.2 & 62.3 \\
\hline \multirow{2}{*}{ D $\alpha$-L-Fuc $p 2 S 4 S-(1 \rightarrow$} & $5.68 /$ & 4.47| & $4.17 /$ & $4.86 /$ & $4.90 /$ & $1.37 \mid$ \\
\hline & 97.7 & 76.6 & 67.8 & 82.5 & 67.5 & 16.9 \\
\hline \multirow{2}{*}{ E $\alpha$-L-Fuc $p 3 S 4 S-(1 \rightarrow$} & $5.34 /$ & $3.95 /$ & $4.53 /$ & $4.99 /$ & $4.80 /$ & $1.37 /$ \\
\hline & 100.5 & 67.6 & 76.6 & 80.6 & 67.6 & 17.2 \\
\hline \multirow{2}{*}{ F $\alpha$-L-Fuc $p 4 S-(1 \rightarrow$} & $5.40 /$ & $3.82 /$ & $4.04 /$ & $4.77 /$ & $4.80 /$ & $1.37 /$ \\
\hline & 99.6 & 69.7 & 70.0 & 82.4 & 67.6 & 17.2 \\
\hline \multirow{2}{*}{$\mathrm{G} \rightarrow 3)-\beta-\mathrm{D}-\mathrm{Gal} p \mathrm{NAc} 4 S-(1 \rightarrow$} & $4.47 /$ & $3.38 /$ & $3.59 /$ & $4.81 /$ & $4.02 /$ & 3.81/ \\
\hline & 105.1 & 73.9 & 75.2 & 77.2 & 76.2 & 62.3 \\
\hline \multirow{2}{*}{$\mathbf{H} \rightarrow 2)-\alpha-\mathrm{L}-\mathrm{Fuc} p 4 S-(1 \rightarrow$} & $5.28 /$ & $4.28 /$ & $4.00 /$ & $4.84 /$ & \multirow{2}{*}{$\mathrm{NdNd}$} & 1.37/ \\
\hline & 99.1 & 72.8 & 68.6 & 82.5 & & 17.2 \\
\hline \multirow{2}{*}{ J $\alpha$-L-Fucp $3 S 4 S-(1 \rightarrow$} & $5.41 /$ & 4.19/ & $4.69 /$ & $4.99 /$ & \multirow{2}{*}{$\mathrm{NdNd}$} & $1.37 /$ \\
\hline & 99.6 & 70.9 & 76.6 & 80.6 & & 17.2 \\
\hline
\end{tabular}

$\mathrm{Nd}$-not determined.

\section{A}

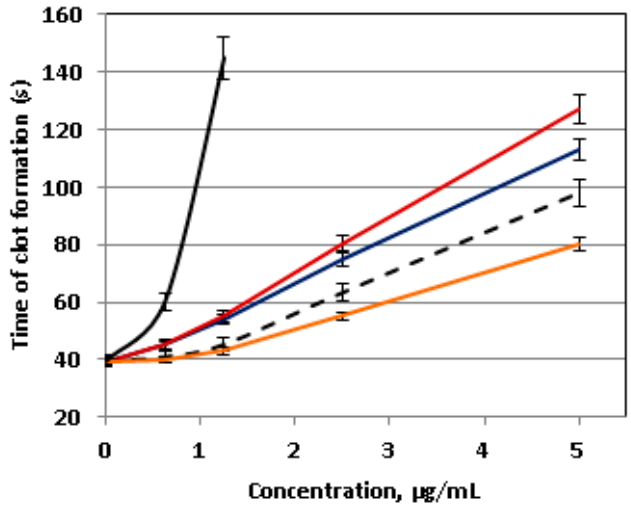

C

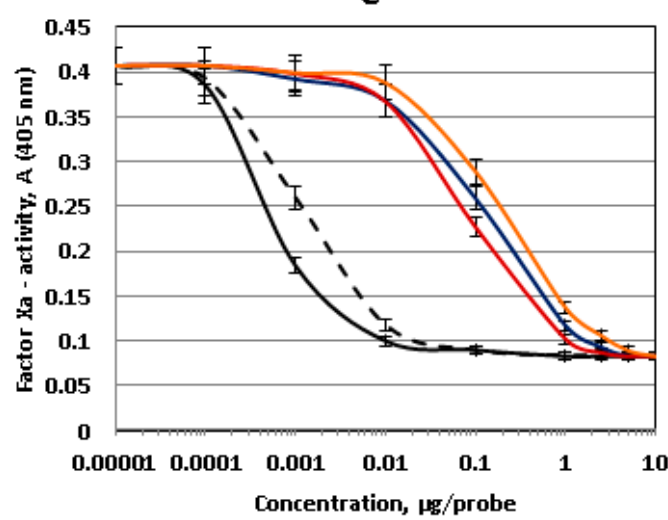

B

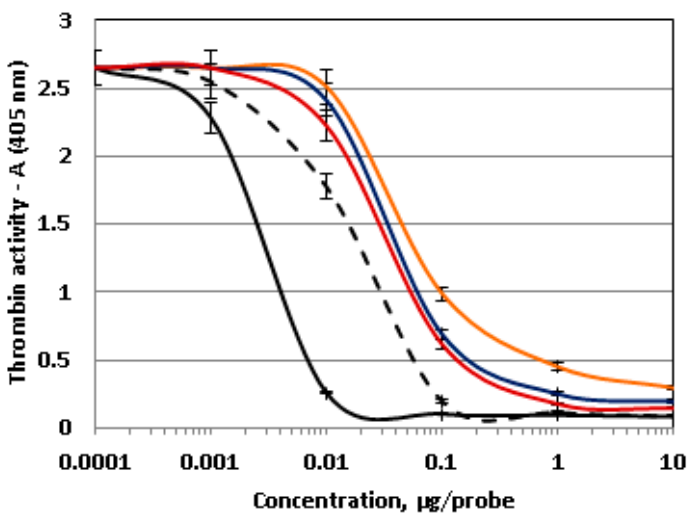

D

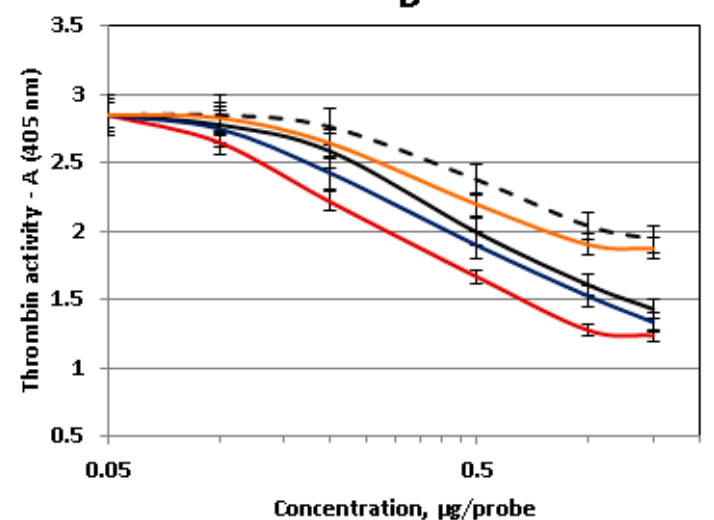

Figure 5. Anticoagulant activity of polysaccharides PC (blue), HH (red), CD (orange), heparin (black), and enoxaparin (dotted line). (A) Activate partial thromboplastin time (APTT) assay, (B) anti-Ila-activity in the presence of antithrombin III (ATIII), (C) anti-Xa-activity in the presence of ATIII, and (D) anti-IIa-activity without ATIII. $n=4, p<0.05$. 
Thrombin and factor $\mathrm{Xa}$ are considered to be the main players in the coagulation cascade $[1,6]$. These serine proteases could be inhibited by ATIII, and this interaction is significantly increased in the presence of heparinoids. Therefore, we then studied the ability of the polysaccharides to potentiate the inhibition of thrombin and factor Xa in the presence of ATIII. In these experiments, all of the studied polysaccharides demonstrated the activity, but the values of the effects were lower than those of heparinoids (Figure 5B,C). Interesting results were obtained in the experiment with thrombin but without ATIII (Figure 5D). HH inhibited thrombin activity more effectively than PC and CD, and this phenomenon may be explained by the presence of disaccharide branches in HH. Notably, the activity of HH and PC was higher than that of heparin in this experiment. Previously, direct thrombin inhibition was described for fucoidans from brown seaweeds, the polysaccharides enriched in fucose content [31]. This mechanism might be taken into consideration, as it could impact the coagulation cascade.

\section{Materials and Methods}

\subsection{General Methods}

The procedures for the determination of neutral monosaccharides, sulfate, and uronic acids were described previously [32-34]. The molecular weights of polysaccharides were evaluated by chromatographic comparison with standard pullulans [28].

\subsection{Isolation of Polysaccharides}

The samples of sea cucumber Holothuria hilla were collected in the summer of 1990, on the seashore of D'Arros Island (Seyshelles) at a depth of $10 \mathrm{~m}$ by scuba divers. The taxonomic identification was made by Prof. V.S. Levin of the G.B. Elyakov Pacific Institute of Bioorganic Chemistry of the Far Eastern Branch of the Russian Academy of Sciences (PIBOC FEB RAS). The samples of Paracaudina chilensis were collected in the Trinity Bay, Peter the Great Gulf, the Sea of Japan in the summer of 2019 at a depth of 5-7 m. The taxonomic identification was carried out by Boris B. Grebnev (PIBOC FEB RAS). Both animals were fixed with ethanol. The sea cucumbers were cut into pieces, extracted twice with refluxed $70 \% \mathrm{EtOH}$, and the residue of animal material was air-dried.

According to the conventional procedure [27], dried and minced biomass of $H$. hilla (40 g) was suspended in $300 \mathrm{~mL}$ of $0.1 \mathrm{M}$ sodium acetate buffer $(\mathrm{pH} 6.0)$, containing papain ( $1 \mathrm{~g}$ ), ethylenediaminetetraacetic acid (EDTA) (0.4 g), and L-cysteine hydrochloride $(0.2 \mathrm{~g})$, and incubated at $45-50{ }^{\circ} \mathrm{C}$ for $24 \mathrm{~h}$. After centrifugation, an aqueous hexadecyl-trimethylammonium bromide solution $(10 \%, 30 \mathrm{~mL})$ was added to the supernatant; the resulting precipitate was isolated by centrifugation and washed successively with water and ethanol. Then, it was stirred with a $20 \%$ ethanolic NaI solution $(5 \times 40 \mathrm{~mL})$ for 2-3 days, washed with ethanol, dissolved in water, and lyophilized to obtain the crude polysaccharide preparation HH-SP, yield $1.9 \mathrm{~g}(4.7 \%)$, composition: Fuc 16.6\%, uronic acids 3.0\%, GlcN 2.1\%, GalN 5.2\%, Gal 2.1\%, and $\mathrm{SO}_{3} \mathrm{Na} 15.8 \%$. An aqueous solution of HH-SP (249 $\mathrm{mg}$ in $50 \mathrm{~mL}$ ) was placed on a column $(3 \times 10 \mathrm{~cm})$ with DEAE (Diethylaminoethyl)-Sephacel in $\mathrm{Cl}^{-}$form and eluted with water, followed by a $\mathrm{NaCl}$ solution of increasing concentration $(0.5,0.75,1.0$, and $1.5 \mathrm{M})$, each time until the absence of a positive reaction of eluate for carbohydrates [35]. Fractions were desalted on a Sephadex G-15 (Sigma-Aldrich, St. Louis, MO, USA. Catalog number: G15120) column and lyophilized. According to composition (Table 1), the fraction eluted with $1.0 \mathrm{M} \mathrm{NaCl}$ was designated as $\mathbf{H H}$ and studied further as preparation of FCS. Similar treatment of P. chilensis biomass ( $45 \mathrm{~g}$ ) gave rise to crude polysaccharide preparation PC-SP, yield $1.2 \mathrm{~g}(2.7 \%)$, and preparation of FCS eluted from the DEAE-Sephadex with $1.0 \mathrm{M} \mathrm{NaCl}$ was designated as PC (Table 1).

\subsection{NMR Spectroscopy}

The NMR spectra were recorded using Zelinsky Institute Shared Research Facilities Center. The sample preparation and the conditions of the experiments were described previously [7]. 


\subsection{Clotting Time Assay}

The APTT test was performed as described previously [14]. Heparin (Sigma-Aldrich, St. Louis, MO, USA. Catalog number: 51550), enoxaparin (Clexane ${ }^{\circledR}$, Sanofi, Paris, France), and FCS CD were used as references.

\subsection{Effect of Polysaccharides on Thrombin or Factor Xa Inactivation by Antithrombin III}

Both experiments were carried out at $37^{\circ} \mathrm{C}$ in 96-well plates using MultiscanGo (Thermo Fisher Scientific, Stockholm, Sweden). Tris- $\mathrm{HCl}$ buffer was used as a control.

A ReaChrom ATIII test kit (Renam, Moscow, Russia) was used for the measurement of thrombin activity. A solution of a polysaccharide sample (PC, HH, CD, heparin, or enoxaparin) $(20 \mu \mathrm{L})$ with concentrations of 500, 50, 5, 0.5, and $0.05 \mu \mathrm{g} / \mathrm{mL}$ in Tris- $\mathrm{HCl}$ buffer was added to $50 \mu \mathrm{L}$ of a solution of ATIII $(0.2 \mathrm{U} / \mathrm{mL})$ in Tris- $\mathrm{HCl}$ buffer $(0.15 \mu \mathrm{M}, \mathrm{pH}$ 8.4). After a 3-min incubation, an aqueous solution of thrombin $(50 \mu \mathrm{L}, 20 \mathrm{U} / \mathrm{mL})$ was added, and the mixture was incubated for $2 \mathrm{~min}$. Then, a chromogenic substrate ( $50 \mu \mathrm{L}, 2 \mathrm{mM})$ was added, and the mixture was kept for $2 \mathrm{~min}$. Absorbance of $p$-nitroaniline (405 nm) was measured.

A ReaChrom Heparin kit (Renam, Moscow, Russia) was used for the measurement of factor Xa activity. A solution of a polysaccharide sample (PC, HH, CD, heparin, or enoxaparin) ( $20 \mu \mathrm{L})$ with concentrations of 500, 50, 5, 0.5, and $0.05 \mu \mathrm{g} / \mathrm{mL}$ in Tris- $\mathrm{HCl}$ buffer was added to $50 \mu \mathrm{L}$ of a solution of ATIII $(0.5 \mathrm{U} / \mathrm{mL})$ in Tris- $\mathrm{HCl}$ buffer. After a 3-min incubation, an aqueous solution of factor Xa $(50 \mu \mathrm{L}$, $2 \mathrm{U} / \mathrm{mL}$ ) was added, and the mixture was incubated for $2 \mathrm{~min}$. The mixture was worked up, treated with chromogenic substrate, and analyzed as described above.

\subsection{Effect of Polysaccharides on Thrombin Inactivation without ATIII}

A ReaChrom ATIII test kit (Renam, Moscow, Russia) was used for the experiments. An aqueous solution of thrombin $(50 \mu \mathrm{L}, 20 \mathrm{U} / \mathrm{mL})$ and a solution of a polysaccharide sample (PC, HH, CD, heparin, or enoxaparin) $(20 \mu \mathrm{L})$ with concentrations of $750,500,250,100$, and $50 \mu \mathrm{g} / \mathrm{mL}$ in Tris-HCl buffer were added to $50 \mu \mathrm{L}$ of Tris-HCl buffer. The mixture was incubated for $3 \mathrm{~min}$. Then, $50 \mu \mathrm{L}$ of a chromogenic substrate $(2 \mathrm{mM})$ was added, and the incubation was continued for $2 \mathrm{~min}$. The absorbance of $p$-nitroaniline ( $405 \mathrm{~nm}$ ) was measured. Tris- $\mathrm{HCl}$ buffer was used as a control.

\subsection{Statistical Analysis}

All biological experiments were performed in quadruplicate $(n=4)$. The results are presented as Mean \pm SD. Statistical significance was determined with Student's $t$ test. The $p$ values less than 0.05 were considered significant.

\section{Conclusions}

Two new sulfated polysaccharides PC and $\mathbf{H H}$ were isolated from the sea cucumbers Paracaudina chilensis and Holothuria hilla, respectively. The main components of these biopolymers were GlcA, GalNAc, Fuc, and sulfate, indicating PC and HH as fucosylated chondroitin sulfates. Based on the data of the NMR spectra, both polysaccharides were shown to contain a chondroitin core $[\rightarrow 3)-\beta$-D-GalNAc- $(1 \rightarrow 4)-\beta$-D-GlcA- $(1 \rightarrow]_{n}$, bearing sulfated fucosyl branches at O-3 of every GlcA residue in the chain. These fucosyl residues were different in their pattern of sulfation: PC contained Fuc2S4S and Fuc4S in a ratio of 2:1, while HH included Fuc2S4S, Fuc3S4S, and Fuc4S in a ratio of 1.5:1:1. Moreover, some GalNAc residues in $\mathbf{H H}$ were found to contain the unusual disaccharide branch Fuc4S- $(1 \rightarrow 2)$-Fuc3S4S-( $1 \rightarrow$ at O-6. Sulfated GalNAc4S6S and GalNAc4S units were found in a ratio of 3:2 in PC and 2:1 in $\mathbf{H H}$. Both polysaccharides demonstrated significant anticoagulant activity in the clotting time assay, which is connected with the ability of these FCSs to potentiate inhibition of thrombin and factor Xa in the presence of ATIII and with the direct inhibition of thrombin in the absence of any cofactors. 
Supplementary Materials: The following are available online at http://www.mdpi.com/1660-3397/18/11/540/s1, Figure S1: The COSY NMR spectra of polysaccharides PC (I) and HH (II), Figure S2: The ROESY NMR spectra of polysaccharides PC (I) and HH (II), Figure S3: The TOCSY NMR spectra of polysaccharides PC (I) and HH (II), and Figure S4: The calculation of the ratios of units H:E and D:E:F in polysaccharide HH using the integral intensities of the respective $\mathrm{H}-1$ signals.

Author Contributions: Conceptualization, A.I.U., N.E.N., V.A.S., and N.E.U.; methodology, A.I.U., M.I.B., and N.E.U.; analysis, M.I.B., N.E.U., A.S.D, and A.S.S.; investigation, M.I.B., N.E.U., A.S.D., A.S.S., and A.I.U.; resources, B.B.G. and A.S.S.; original draft preparation, N.E.U. and A.I.U.; review and editing, all authors; supervision, A.I.U., N.E.N., and V.A.S. All authors have read and agreed to the published version of the manuscript.

Funding: This research was funded by the Russian Science Foundation, grant number 19-73-20240.

Conflicts of Interest: The authors declare no conflict of interest. The funders had no role in the design of the study; in the collection, analyses, or interpretation of data; in the writing of the manuscript; or in the decision to publish the results.

\section{References}

1. Pomin, V.H. Holothurian fucosylated chondroitin sulfates. Mar. Drugs 2014, 12, 232-254. [CrossRef] [PubMed]

2. Myron, P.; Siddiquee, S.; Azad, S.A. Fucosylated chondroitin sulfate diversity in sea cucumbers: A review. Carbohydr. Polym. 2014, 112, 173-178. [CrossRef]

3. Pomin, V.H.; Vignovich, W.P.; Gonzales, A.V.; Vasconcelos, A.A.; Mulloy, B. Galactosaminoglycans: Medical Applications and Drawbacks. Molecules 2019, 24, 2803. [CrossRef]

4. Ustyuzhanina, N.E.; Bilan, M.I.; Nifantiev, N.E.; Usov, A.I. New insight on the structural diversity of holothurian fucosylated chondroitin sulfates. Pure Appl. Chem. 2019, 91, 1065-1071. [CrossRef]

5. Chen, S.; Xue, C.; Yin, L.; Tang, Q.; Yu, G.; Chai, W. Comparison of structures and anticoagulant activities of fucosylated chondroitin sulfates from different sea cucumbers. Carbohydr. Polym. 2011, 83, 688-696. [CrossRef]

6. Mourão, P.A.S. Perspective on the use of sulfated polysaccharides from marine organisms as a source of new antithrombotic drugs. Mar. Drugs 2015, 13, 2770-2784. [CrossRef] [PubMed]

7. Ustyuzhanina, N.E.; Bilan, M.I.; Dmitrenok, A.S.; Tsvetkova, E.A.; Shashkov, A.S.; Stonik, V.A.; Nifantiev, N.E.; Usov, A.I. Structural characterization of fucosylated chondroitin sulfates from sea cucumbers Apostichopus japonicus and Actinopyga mauritiana. Carbohydr. Polym. 2016, 153, 399-405. [CrossRef]

8. Ustyuzhanina, N.E.; Bilan, M.I.; Dmitrenok, A.S.; Nifantiev, N.E.; Usov, A.I. Two fucosylated chondroitin sulfates from the sea cucumber Eupentacta fraudatrix. Carbohydr. Polym. 2017, 164, 8-12. [CrossRef]

9. Chen, S.; Li, G.; Wu, N.; Guo, X.; Liao, N.; Ye, X.; Liu, D.; Xue, C.; Chai, W. Sulfation pattern of the fucose branch is important for the anticoagulant and antithrombotic activities of fucosylated chondroitin sulfates. Biochim. Biophys. Acta 2013, 1830, 3054-3066. [CrossRef]

10. Soares, P.A.G.; Ribeiro, K.A.; Valente, A.P.; Capillé, N.V.; Oliveira, S.-N.M.C.G.; Tovar, A.M.F.; Pereira, M.S.; Vilanova, E.; Mourão, P.A.S. A unique fucosylated chondroitin sulfate type II with strikingly homogeneous and neatly distributed $\alpha$-fucose branches. Glycobiology 2018, 28, 565-579. [CrossRef]

11. Carvalhal, F.; Cristelo, R.R.; Resende, D.I.S.P.; Pinto, M.M.M.; Sousa, E.; Correia-da-Silva, M. Antithrombotics from the Sea: Polysaccharides and Beyond. Mar. Drugs 2019, 17, 170. [CrossRef]

12. Mourão, P.A.S.; Boisson-Vidal, C.; Tapon-Bretaudiere, J.; Drouet, B.; Bros, A.; Fischer, A. Inactivation of thrombin by a fucosylated chondroitin sulfate from echinoderm. Thromb. Res. 2001, 102, 167-176.

13. Liu, X.; Hao, J.; Shan, X.; Zhang, X.; Zhao, X.; Li, Q.; Wang, X.; Cai, C.; Li, G.; Yu, G. Antithrombotic activities of fucosylated chondroitin sulfates and their depolymerized fragments from two sea cucumbers. Carbohydr. Polym. 2016, 152, 343-350. [CrossRef]

14. Ustyuzhanina, N.E.; Bilan, M.I.; Dmitrenok, A.S.; Borodina, E.Y.; Stonik, V.A.; Nifantiev, N.E.; Usov, A.I. A highly regular fucosylated chondroitin sulfate from the sea cucumber Massinium magnum: Structure and effects on coagulation. Carbohydr. Polym. 2017, 167, 20-26. [CrossRef]

15. Wu, M.; Wen, D.; Gao, N.; Xiao, C.; Yang, L.; Xu, L.; Lian, W.; Peng, W.; Jiang, J.; Zhao, J. Anticoagulant and antithrombotic evaluation of native fucosylated chondroitin sulfates and their derivatives as selective inhibitors of intrinsic factor Xase. Eur. J. Med. Chem. 2015, 92, 257-269. [CrossRef]

16. Yan, L.; Li, J.; Wang, D.; Ding, T.; Hu, Y.; Ye, X.; Linhardt, R.J.; Chen, S. Molecular size is important for the safety and selective inhibition of intrinsic factor Xase for fucosylated chondroitin sulfate. Carbohydr. Polym. 2017, 178, 180-189. [CrossRef] 
17. Yan, L.; Wang, D.; Zhu, M.; Yu, Y.; Zhang, F.; Ye, X.; Linhardt, R.J.; Chen, S. Highly purified fucosylated chondroitin sulfate oligomers with selective intrinsic factor Xase complex inhibition. Carbohydr. Polym. 2019, 222, 115025. [CrossRef]

18. Pomin, V.H.; Mourão, P.A.S. Specific sulfation and glycosylation-A structural combination for the anticoagulation of marine carbohydrates. Front. Cell. Infect. Microbiol. 2014, 4, 33. [CrossRef]

19. Panagos, C.G.; Thomson, D.S.; Moss, C.; Hoghes, A.D.; Kelly, M.S.; Liu, Y.; Chai, W.; Venkatasamy, R.; Spina, D.; Page, C.P.; et al. Fucosylated chondroitin sulfates from the body wall of the sea cucumber Holothuria forskali. Conformation, selectin binding, and biological activity. J. Biol. Chem. 2014, 289, 28284-28298. [CrossRef]

20. Ustyuzhanina, N.E.; Bilan, M.I.; Dmitrenok, A.S.; Shashkov, A.S.; Ponce, N.M.A.; Stortz, C.A.; Nifantiev, N.E.; Usov, A.I. Fucosylated chondroitin sulfate from the sea cucumber Hemioedema spectabilis: Structure and influence on cell adhesion and tubulogenesis. Carbohydr. Polym. 2020, 234, 115895. [CrossRef]

21. Li, Q.; Cai, C.; Chang, Y.; Zhang, F.; Linhardt, R.J.; Xue, C.; Li, G.; Yu, G. A novel structural fucosylated chondroitin sulfate from Holothuria mexicana and its effects on growth factors binding and anticoagulation. Carbohydr. Polym. 2018, 181, 1160-1168. [CrossRef]

22. Wu, J.; Yi, Y.-H.; Tang, H.-F.; Wu, H.-M. Hillasides A and B, two new cytotoxic triterpene glycosides from the sea cucumber Holothuria hilla Lesson. J. Asia Nat. Prod. Res. 2007, 9, 609-615. [CrossRef]

23. Wu, J.; Yi, Y.-H.; Tang, H.F.; Zou, Z.-R.; Wu, H.-M. Structure and cytotoxicity of a new lanostan-type triterpene glycoside from the sea cucumber Holothuria hilla. Chem. Biodivers. 2006, 3, 1249-1254. [CrossRef]

24. Kalinin, V.I.; Malyutin, A.N.; Stonik, V.A. Caudinoside A-A new triterpene glycoside from the holothurian Paracaudina ransonetii. Chem. Nat. Compd. 1986, 22, 355-356. [CrossRef]

25. Suzuki, T. Amino acid sequence of a major globin from the sea cucumber Paracaudina chilensis. Biochim. Biophys. Acta 1989, 998, 292-296. [CrossRef]

26. Zeng, M.; Xiao, F.; Li, B.; Zhao, Y.; Liu, Z.; Dong, S. Study on free radical scavenging activity of sea cucumber (Paracaudina chinens var.) gelatin hydrolysate. J. Ocean. Univ. China 2007, 6, 255-258. [CrossRef]

27. Vieira, R.P.; Mulloy, B.; Mourão, P.A.S. Structure of a fucose-branched chondroitin sulfate from sea cucumber. Evidence for the presence of 3-O-sulfo- $\beta$-D-glucuronosyl residues. J. Biol. Chem. 1991, 266, 13530-13536.

28. Guo, X.; Condra, M.; Kimura, K.; Berth, G.; Dautzenberg, H.; Dubin, P.L. Determination of molecular weight of heparin by size exclusion chromatography with universal calibration. Anal. Biochem. 2003, 312, 33-39. [CrossRef]

29. Pomin, V.H. NMR structural determination of unique invertebrate glycosaminoglycans endowed with medical properties. Carbohydr. Res. 2015, 413, 41-50. [CrossRef]

30. Ustyuzhanina, N.E.; Bilan, M.I.; Panina, E.G.; Sanamyan, N.P.; Dmitrenok, A.S.; Tsvetkova, E.A.; Ushakova, N.A.; Shashkov, A.S.; Nifantiev, N.E.; Usov, A.I. Structure anf anti-inflammatory activity of a new unusual fucosylated chondroitin sulfate from Cucumaria djakonovi. Mar. Drugs 2018, 16, 389. [CrossRef]

31. Ustyuzhanina, N.E.; Ushakova, N.A.; Zyuzina, K.A.; Bilan, M.I.; Elizarova, A.L.; Somonova, O.V.; Madzhuga, A.V.; Krylov, V.B.; Preobrazhenskaya, M.E.; Usov, A.I.; et al. Influence of fucoidans on hemostatic system. Mar. Drugs 2013, 11, 2444-2458. [CrossRef]

32. Bilan, M.I.; Grachev, A.A.; Ustuzhanina, N.E.; Shashkov, A.S.; Nifantiev, N.E.; Usov, A.I. Structure of a fucoidan from the brown seaweed Fucus evanescens C.Ag. Carbohydr. Res. 2002, 337, 719-730. [CrossRef]

33. Bilan, M.I.; Zakharova, A.N.; Grachev, A.A.; Shashkov, A.S.; Nifantiev, N.E.; Usov, A.I. Polysaccharides of algae: 60. Fucoidan from the Pacific brown alga Analipus japonicus (Harv.) Winne (Ectocarpales, Scytosiphonaceae). Russ. J. Bioorg. Chem. 2007, 33, 38-46. [CrossRef]

34. Usov, A.I.; Bilan, M.I.; Klochkova, N.G. Polysaccharides of algae: 48. Polysaccharide composition of several calcareous red algae: Isolation of alginate from Corallina pilulifera P. et R. (Rhodophyta, Corallinaceae). Bot. Mar. 1995, 38, 43-51. [CrossRef]

35. Dubois, M.; Gilles, K.A.; Hamilton, J.K.; Rebers, P.A.; Smith, F. Colorimetric method for determination of sugars and related substances. Anal. Chem. 1956, 28, 350-356. [CrossRef]

Publisher's Note: MDPI stays neutral with regard to jurisdictional claims in published maps and institutional affiliations. 